\title{
Arcos de triunfo efímeros erigidos en la ciudad de A Coruña para los monarcas que la visitaron en la segunda mitad del siglo XIX
}

\section{Ephemeral triumphal archs erected in the city of A Coruña for the monarchs who visited it in the second half of the 19th century}

\author{
LuCía M. VILLAsuso FeRnándeZ
}

\begin{abstract}
RESUMEN
ABSTRACT

En el presente artículo se exponen varios ejemplos de arcos de triunfo -tipología principal de la arquitectura efímera conmemorativa - realizados en diferentes materiales y estilos, para festejar la llegada a la ciudad de A Coruña de los dos monarcas españoles que reinaron en la segunda mitad del siglo xx. Estos dos monarcas fueron Isabel II -que en 1858 vino para inaugurar las obras del ferrocarril-y su hijo Alfonso XII, quien vino posteriormente y en más ocasiones, para reconocer sus territorios o inaugurar

In the present article some examples of arches of triumph are exhibited - main typology of commemorative ephemeral architecture - created in various materials and styles to celebrate the arrival of the two Spanish monarchs to the city of $A$ Coruña, who reigned in the second half of the 19th century. These monarchs were Isabel II -who came here in 1858 to inaugurate the works of the railway- and her son Alfonso XII, who came later and on more occasions to visit his territories or to inaugurate the railway.
\end{abstract} la línea de ferrocarril.

${ }^{1}$ Doctoranda en Historia del Arte, UNED. E-mail: Imvf@ole.com 


\section{PALABRAS CLAVE KEYWORDS \\ Arquitectura, efímera, arco de triunfo, conmemorativo, A Coruña, Isabel II, Alfonso XII, siglo XIX. \\ Architecture, ephemeral, triumphal arch, commemorative, A Coruña, Isabel II, Alfonso XII, 19th century.}

\section{ENTRADAS Y ARCOS TRIUNFALES EN A CORUÑA}

Los arcos de triunfo efímeros entroncan formalmente con aquellos por los que pasaba el ejército romano victorioso para obtener la purificación simbólica después de haberse manchado de sangre en la batalla, aunque a partir del siglo xv dejan de tener ese carácter exclusivamente castrense y se emplean también para festejar desposorios, exequias, el recuerdo de un hecho, pero sobre todo, para celebrar la llegada de un personaje importante, que era recibido a las puertas de la ciudad y conducido bajo palio hasta el centro de la misma acompañado por las figuras más representativas de la sociedad, ordenadas de manera estrictamente jerárquica, tal y como sucedió en esta ciudad en el recibimiento de Carlos I o de Felipe II.

Con motivo de una visita importante se realizaron asimismo modificaciones urbanísticas y se levantaron arquitecturas efímeras que devinieron permanentes - como los arcos de triunfo erigidos para Carlos III en la calle Alcalá de Madrid o para Napoleón en París (arco de L'Etoile)—, pero destacaron - tanto a nivel cualitativo como cuantitativo- las obras efímeras, las arquitecturas falsas y engañosas realizadas con materiales perecederos que se destruyeron cuando el evento finalizó, motivo por el que no se conservaron esas fachadas, obeliscos, pirámides y columnas conmemorativas - además de los arcos de triunfo- que se utilizaron para impresionar al espectador y olvidar la situación del momento, generalmente más precaria que la que se mostraba.

En cuanto a la ubicación de las arquitecturas efímeras y más concretamente los arcos de triunfo, generalmente se situaban en la puerta principal de la ciudad, en las calles o plazas mayores, en las calles de los gremios que habían favorecido su construcción, o en el recorrido hasta la iglesia principal o hasta el alojamiento del invitado, en definitiva, en puntos estratégicos de la ciudad donde posiblemente ya se habían erigido otras arquitecturas efímeras con anterioridad. Así, si el arco de triunfo se situaba en una calle, éste tenía dos lados y si se situaba en una plaza, tenía cuatro; y dependiendo de la importancia del personaje agasajado y de la situación económica del promotor, el arco tenía uno o tres vanos, siguiendo la tipología de los arcos de triunfo romanos. 
En la elaboración de las arquitecturas efímeras - y en concreto en los arcos de triunfo- participaban los más afamados artistas de la ciudad, que aunaban esfuerzos para combinar adecuadamente elementos que daban forma a lo simbólico. Y como toda comunidad tiene unos sistemas de comunicación establecidos, el programa iconográfico estaba generalmente relacionado con el ilustre pasado de la ciudad, su legendaria fundación, sus santos patronos, las vivencias políticas del momento, la mitología, la religión, la genealogía del monarca o con el motivo de su viaje, siendo la figura mitológica de Hércules la más empleada en la ciudad de $\mathrm{A}$ Coruña por ser éste el origen legendario de la misma.

También puede afirmarse que la arquitectura efímera generalmente seguía los cánones de la arquitectura permanente en cuanto a estructura, mientras que a nivel decorativo era un ejemplo o ensayo para la arquitectura permanente, ya que a la arquitectura efímera se le añadía una gran cantidad de elementos decorativos como banderolas, escudos y figuras alegóricas - al ejército, a la monarquía y a la propia ciudad - para esconder la precariedad de los materiales de la estructura, también efímeros, de escaso coste y a imitación de otros lujosos, siendo los más habituales la madera, el yeso y el lienzo, aunque existen también ejemplos de arcos de triunfo realizados con elementos lumínicos y vegetales, de los que apenas hay imágenes porque — se cree- fueron menos importantes o más efímeros, dado que el follaje - y las flores en concreto- están más relacionadas con el paso del tiempo y la finitud.

En el Archivo Histórico de A Coruña hemos hallado documentos relacionados con la elaboración de arcos de triunfo lumínicos, destacando en número los creados para las fiestas de M. ${ }^{a}$ Pita de finales del siglo XIX. Así, en las fiestas de María Pita de 1889 se pagó «a Manuel Martínez, por importe de varas para formar arcos y colocar en estos faroles en los jardines de Méndez Núñez, según recibo n. ${ }^{\circ} 55$, 3'90 Ptas.»'. En las de 1891 se quemaron fuegos artificiales bajo la dirección de los pirotécnicos "Hijos de Alonso": Uno de ellos era «un arco triunfal de estilo gótico compuesto de tres plantones con infinidad de bengalas en finísimos colores y transformándose en tres grandes galerías de fuego chinesco »3. Para la iluminación del paseo de Méndez Núñez durante las fiestas de María Pita de 1896 se presentaron varias propuestas, contratándose finalmente la de los «Hermanos Treviño», en la que "se colocarán cinco arcos en la entrada del paseo, con rombos intermedios y con la inscripción "Paseo de Méndez Núñez". A la conclusión del paseo se colocarán otros cinco arcos con rombos intermedios. En el centro o cuerpo del paseo se formarán tres túneles de 20 arcos, o sea 60 arcos en total. Del centro de cada arco penderá una araña. De arco a arco se echará una cadena para unir los

\footnotetext{
${ }^{2}$ Archivo Histórico Municipal de A Coruña (AHMC), caja 971.

${ }^{3}$ AHMC, caja 986.
} 
tres arcos y en estas cadenas irán también faroles. De esta manera calculamos se necesitarán de 4500 a 5000 faroles » ${ }^{4}$.

En otros eventos se levantaron arcos de triunfo vegetales como en la celebración de la aprobación de la vía férrea Ponferrada-Coruña a finales de 1864, en la que los señores Martelo y Mesa costearon un arco de triunfo en la calle de San Agustín, que estaba recubierto de boj y flores e iluminado con vasos ${ }^{5}$. Y cuando en 1895 el Ayuntamiento recibe al político Linares Rivas, se ilumina y engalana profusamente la avenida Linares Rivas con banderas y arcos de triunfo de mirtos y flores ${ }^{6}$.

Antes de estudiar los casos concretos de los recibimientos de Isabel II o Alfonso XII hay que recordar que A Coruña es una ciudad periférica, por lo que no cabe esperar que los arcos de triunfo que se levanten en ella para recibir a un personaje ilustre -ni siquiera durante la época barroca - sean colosales, grandiosos o espectaculares como los que se hacían en la capital, al contrario, en comparación con éstos serán más bien escasos en número, sencillos - generalmente clásicos, de un solo vano y dos fachadas-, económicos y reutilizables.

\section{Los arcos de triunfo en honor a Isabel II}

La escasez de fondos del Ayuntamiento y del Círculo de Artesanos (ACAC) -dos de las entidades coruñesas que más arquitecturas efímeras promovieron en la época contemporánea- es un asunto tratado continuamente en sus libros de actas de 1858, año en el que la reina Isabel II visitó A Coruña para inaugurar la línea de ferrocarril, motivo por el que se erigieron dos arcos de triunfo en su honor, aunque se conocen pocos datos de ambos ${ }^{7}$.

Uno fue promovido por el Círculo de Artesanos, quien acordó realizar un gran arco de triunfo desde el edificio de dicha entidad hasta la casa de enfrente, encargando el plano y desarrollo del proyecto a Joaquín Ortiz de Taranco y la dirección de la obra a Francisco Cortés ${ }^{8}$, que costó 3520 reales $^{9}$.

\footnotetext{
${ }^{4}$ AHMC, Fiestas, caja 975.

5 DAVIÑA SÁINZ, S., Historia y descripción de la ciudad de La Coruña de Antonio Rey Escariz (1860-1941), A Coruña, Ayuntamiento de A Coruña, 1996, págs. 311-8.

${ }^{6}$ MARTÍNEZ-BARBEITO, I., «Nuevo homenaje a Linares Rivas» en periódico La Voz de Galicia (LVG), 28/3/1978, pág. 42.

7 «En seguida se acordó se abra una suscripción para ver si se reúnen fondos con el objeto de obsequiar a la llegada a esta ciudad a SS. MM. AA. una vez todas las corporaciones y sociedades de la población se disponen a ello, por cuanto a que el capital con el que cuenta hoy la Sociedad es muy mezquino». Archivo del Círculo de Artesanos de A Coruña (ACAC), Libros de actas (1855-1863), 12/8/1858.

${ }^{8}$ «Luego se trató qué clase de festejos se habían de hacer por parte de la Sociedad para el recibimiento de SS. MM. AA. y unos propusieron adornar la fachada del local, otros que se hiciese un arco que desde la puerta de la casa cogiese la del vecino D. Antonio Aller (enfrente), y después de discutido se
} 


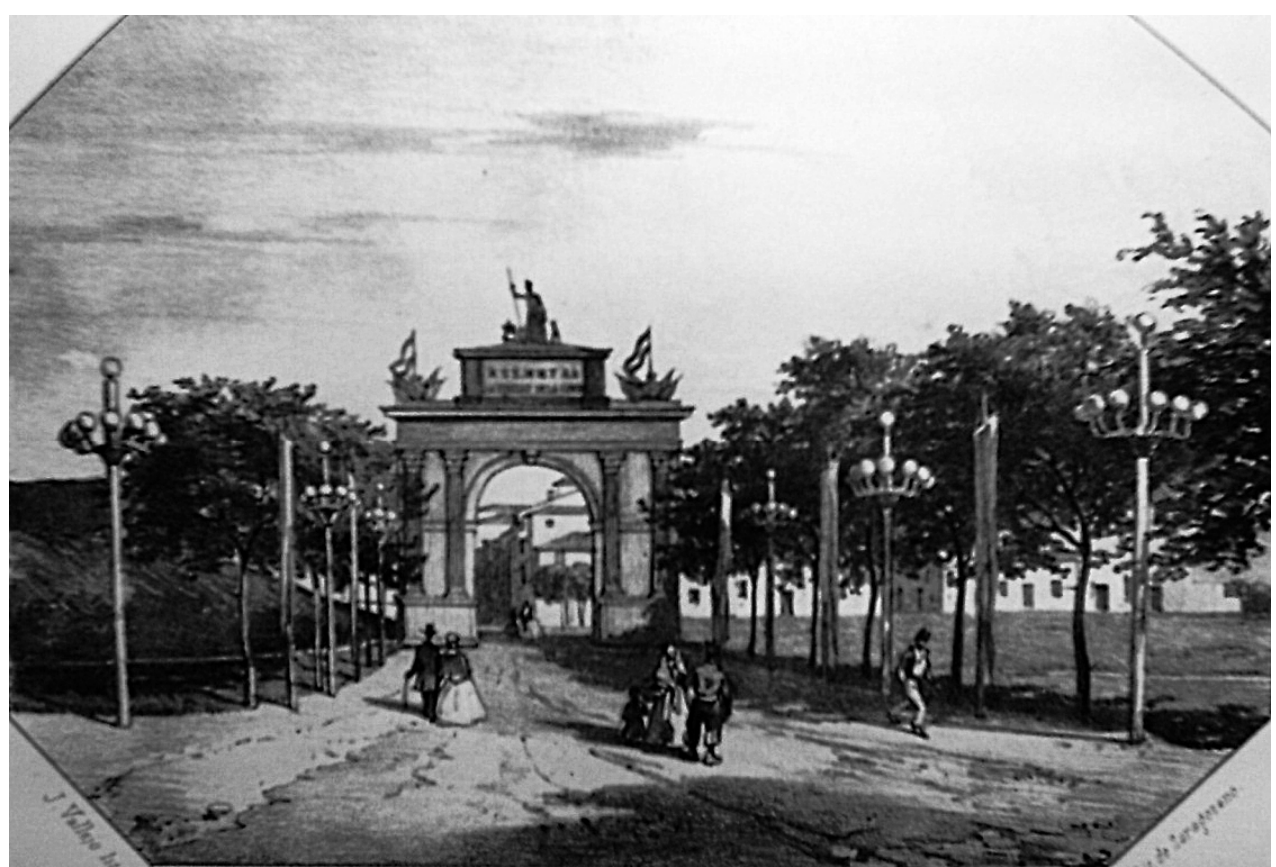

Fig. 1. Arco de triunfo para Isabel II en A Coruña, 1858. RADA Y DELGADO, J., Viaje de SS. MM. AA. por Castilla, León, Asturias y Galicia, 1858, pág. 620.

Del otro arco de triunfo - que recreaba las artes y fue promovido por el Ayuntamiento ${ }^{10}$ - el cronista oficial J. de Dios de la Rada y Delgado no hace comenta-

adoptó realizar éste último y al efecto se comisionó al sr. D. Joaquín Ortiz de Taranco para que conforme con sus conocimientos teóricos y prácticos se sirva de levantar el plano y tenga efecto la idea (mientras que la dirección de la obra se encargó a Francisco Cortés)». ACAC, Libros de actas (18551863), 17/8/1858.

«La Junta, teniendo presente los buenos servicios que prestó a la Sociedad D. Francisco Cortés, alumno de la Escuela de sobrestantes, con motivo de las fiestas de SS. MM. AA. ya dirigiendo el arco, ya otros trabajos de importancia, en agradecimiento a ello, acordó declararle socio de número durante su permanencia como tal alumno en esta ciudad, relevándole del pago de entrada y mensualidades, pudiendo concurrir a los salones de la Sociedad como individuo de ella». Ídem, 26/9/1858.

9 «Presentada en este acto la cuenta de gastos que tuvieron los festejos de SS. MM. AA., incluido el arco y su iluminación en las noches 5-6 y 10-11 de septiembre último que asciende a 3520 reales y habiendo producido la suscripción voluntaria de 1214 reales resulta un déficit contra la Sociedad de 2306. La Junta quedó enterada acordando se expida libramiento por los gastos y cargamen por el importe de la suscripción y que se fije en el Salón la mencionada cuenta para el conocimiento de la Sociedad». Ídem, 8/10/1858.

10 «En medio de la carrera por donde el cortejo debía atravesar, se distinguía el magnífico arco triunfal que el municipio había erigido, en el cual las Artes y las Ciencias se hallaban demostradas en verdaderos atributos». VV.AA., Estancia de SS. MM. y AA. en La Coruña. Reseña descriptiva de los festejos con que la ciudad de La Coruña obsequió a SS. MM. y AA. durante su permanencia en ella, La Coruña, Imprenta D. Domingo Puga, 1858, pág. 9. 


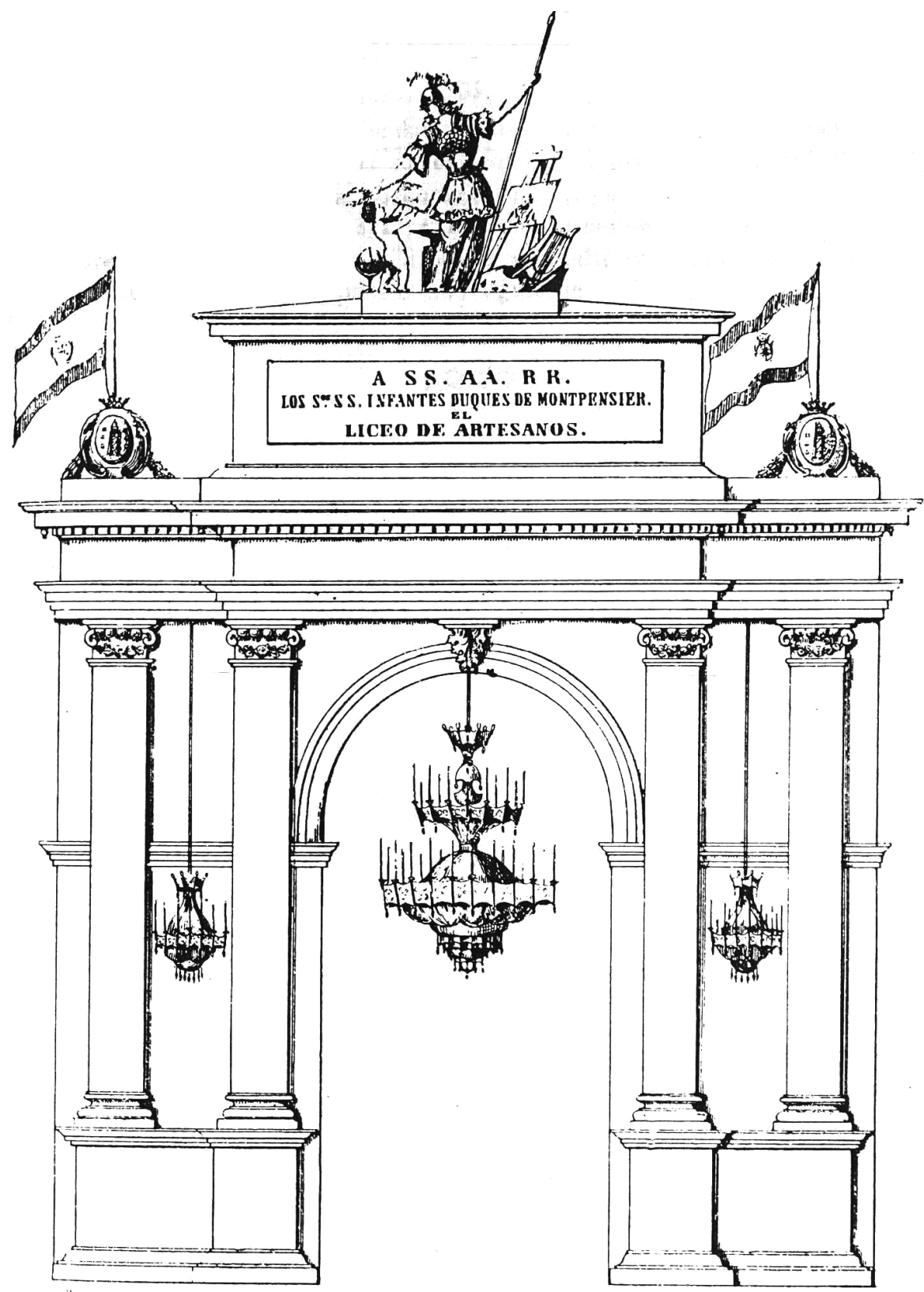

Fig. 2. Arco de triunfo para los duques de Montpensier en A Coruña, 1852. ESTRADA CATOYRA, F., Contribución a la historia de la Reunión Recreativa e Instructiva de Artesanos, La Coruña, Reunión Recreativa e Instructiva de Artesanos, 1986, pág. 34. 
rio alguno aunque curiosamente, en su obra se incluye el dibujo de este arco de triunfo (fig. 1), que casualmente era igual al que el Círculo de Artesanos había encargado seis años antes al afamado artista Benito Diana para recibir a los duques de Montpensier ${ }^{11}$ (fig. 2).

No hay documentos que indiquen el material que se utilizó para su construcción - aunque se supone que sería de madera y yeso-, ni el color o tratamiento de las superficies. De todos modos, se puede observar que es un arco de triunfo clásico de clara influencia romana, con dos fachadas, un sólo vano y cuatro pilastras corintias sobre un zócalo que sostienen un cornisamento sobre el que se situaron banderas y otros elementos decorativos - posiblemente la Torre de Hércules, símbolo de la ciudad retomado constantemente en los festejos públicos coruñeses desde la visita de los Reyes Católicos a finales del siglo xv-, el tarjetón de bienvenida y sobre éste, figuras alusivas a las artes y las ciencias, por lo que se puede afirmar que fue un arco de triunfo poco innovador tanto a nivel formal como iconográfico para ser reconocidos por todas las clases sociales, y similar a los levantados con el mismo fin en Ferrol, Santiago, Gijón o Málaga, aunque en estas ciudades también hubo ejemplos de arcos de triunfo en estilo bizantino y gótico.

Observando ambos arcos de triunfo se puede constatar y afirmar entonces que el arco realizado por el Círculo de Artesanos en 1852 para recibir a los duques de Montpensier fue - muy posiblemente- el que el Ayuntamiento reutilizó posteriormente para la visita de Isabel II, porque como se indicaba en los documentos de la época —-posiblemente de manera inconsciente_-, debido a la precaria situación económica que vivía la Círculo de Artesanos en ese momento, el arco de 1852 se ideó para perdurar y perpetuarse en el tiempo, es decir, fue un arco de triunfo efímero con vocación permanente, o sea, contrario a su naturaleza ${ }^{12}$.

${ }^{11} \mathrm{El}$ arco de triunfo realizado en 1852 medía 42 pies de alto por 36'5 de ancho y 3'5 de espesor, fue construido bajo la dirección del artista y profesor de pintura Benito Diana en sólo 54 horas, se situó en la actual calle Real y costó 3621 reales. Tenía pilastras jónicas (sic), sotobanco y un cornisamento sobre el cual se apreciaban escudos heráldicos de España con el collar del toisón de oro y dos Torres de Hércules con el león sujetando los dos mundos. En medio se colocó el tarjetón para la dedicatoria a los ilustres visitantes y encima del mismo se situó una figura de 10 pies de altura que representaba a diosa de la inteligencia Minerva-Atenea, armada, coronando al genio de las artes y con los atributos de las artes, como el caballete o la lira, evidenciando así el gremio que había promovido la realización del arco y demostrando de este modo la superioridad de las artes y la necesidad de esta facultad para ser artista. Del centro del arco además pendía una araña colosal de estilo gótico y a los lados, cuatro de reducidas proporciones, pertenecientes al mismo estilo. ZEPEDANO, N. y NEIRA DE MOSQUERA, A., SS. AA. RR. los Serenísimos Duques de Montpensier en Galicia, Santiago, Imprenta de D. J. Rey Romero, 1852, pág. 12.

12 «El sr. Diana manifestó que si bien es justo complacer a la autoridad del pueblo, lo único que la Sociedad (...) podía hacer era un arco de triunfo, pero que su coste ascendería de 1500 a 2000 reales, que si el sr. alcalde facilitase para ello al menos 1000, aunque la Sociedad cubriese el resto, además de quedar en el lugar que le corresponde, los materiales del otro arco cubrirían la cantidad en que consistiese aquel». ACAC, Libros de actas (1847-1854), 15/7/1852. 


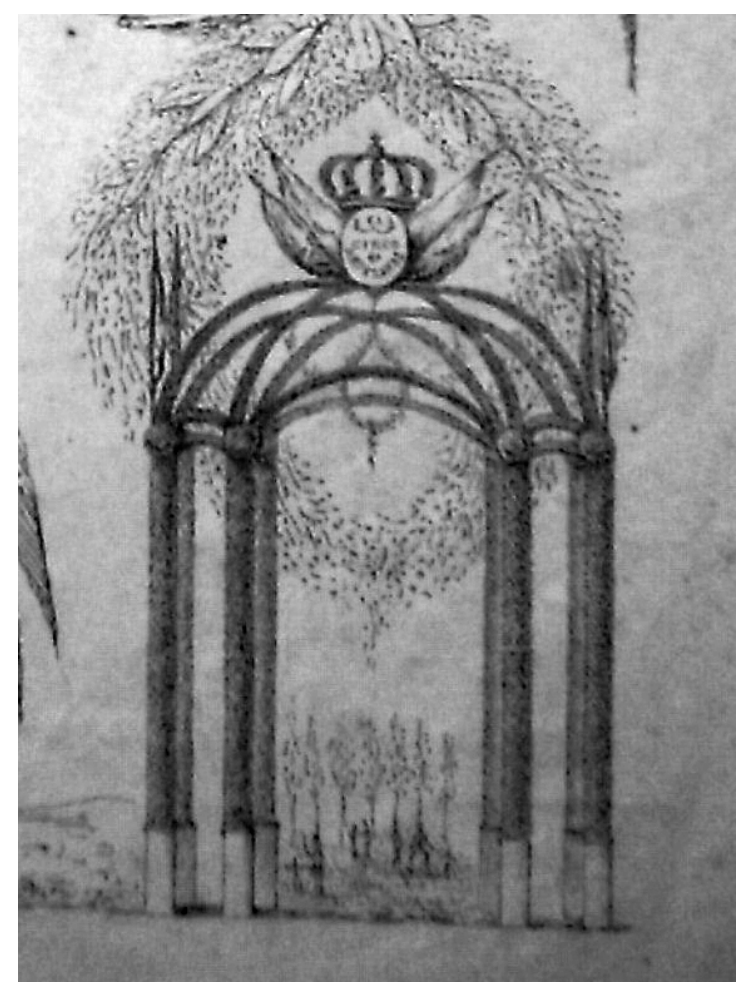

Fig. 3. Arco de triunfo para Isabel Il en A Coruña, 1858. Archivo Histórico Municipal de A Coruña $(A H M C)$, Fondo privado.

Días más tarde despidieron a la reina Isabel II en Monte Salgueiro, donde habían dispuesto «un arco formado de ramaje y vistosas flores» - posiblemente el que se refleja en el cartel conmemorativo (fig. 3)-, y ya en la ciudad de Guitiriz «bajo un arco de frondoso ramaje esperaban a SS. MM.» ${ }^{13}$.

\section{Las decoraciones efímeras para las visitas de Alfonso XII}

Dada la importancia del personaje, la municipalidad coruñesa y su población se volcó en agasajarle no sólo cuando vino en 1858, 1877, 1881 y 1883 -aunque la documentación consultada sea contradictoria ${ }^{14}$ - sino que incluso celebró su bautizo o matrimonio a pesar de que tuvieron lugar en la lejana capital. $792-5$

${ }^{13}$ RADA Y DELGADO, J., Viaje de SS. MM. AA. por Castilla, León, Asturias y Galicia, 1858, págs.

${ }^{14}$ Estudiosos de la historia de A Coruña omiten e incluso niegan que Alfonso XII viniese a la ciudad en 1877 - posiblemente siguiendo la obra de J. García Barros en la que se indica que el monarca se 
A pesar de la escasez de fondos de los que disponía la municipalidad en 1877 - tal y como se aprecia en el libro de actas de ese año ${ }^{15}$-, los gastos de los festejos relacionados con la recepción del monarca fueron elevados, especialmente aquellos referidos a los fuegos de artificio, iluminación, gigantones, embellecimiento de edificios públicos o limosnas entregadas, como sucedía en el resto de las ciudades españolas.

Pero lo verdaderamente interesante es el arco de triunfo que se proyectó para su recibimiento (fig. 4), del que afortunadamente se conserva su plano y pliego de condiciones, así como otros documentos del propio autor -el arquitecto Juan de Ciórraga-, en los que explica las características del $\operatorname{arco}^{16}$ : detalles constructivos, ubicación, coste o almacenamiento y reutilización de las partes, como ya se hiciera con arcos anteriores.

En la primera condición se dice que la obra debía ejecutarse «con toda solidez, perfección y esmero, conforme al plano del proyecto en escala de 1/500 (...) e inspección del arquitecto municipal»", además debía estar totalmente concluido y colocado en el sitio que el alcalde dispondría -al final, en el extremo oeste del paseo de Méndez Núñez- el día 28 de julio de dicho año.

En la segunda condición se indica que el armazón debía construirse con madera de pino de Holanda, exceptuando «los ocho pies derechos principales, que serán de tablones gruesos de pino de tea», y que el exterior sería de bastidores de Holanda y lienzo de lino para pinturas al temple. Además las cornisas, remates, coronas y demás accesorios tenían que ser de pino de Holanda y las banderas, banderolas y gallardetes, de lanilla, «y todo irá pintado al temple, con colores finos, entonación vigorosa, a la par que fina y uniforme, dorando las coronas, escudos, lanzas de banderolas, candelabros y demás partes que lo requieran».

La tercera condición se refiere a la iluminación, que se haría mediante gas, y para lo que se colocarían ocho candelabros de madera, una araña y tantos mecheros con bomba de cristal esmerilado como fuesen precisos, hasta completar el número de 120 mecheros. Se indica también que las tuberías principales o de los

sintió indispuesto y se dirigió directamente de Ferrol a Gijón sin desembarcar en esta ciudad. Pero en el AHMC se han localizado documentos que demuestran lo contrario, como la cuenta de gastos relativos a las limosnas, ágapes, etc.

${ }^{15}$ AHMC, Libros de actas (1881), caja 117, pág. 90.

16 «Dicho arco se construirá de una armazón de madera y bastidores de lienzo pintado, colocándose en una de las embocaduras de la calle Real. En la imposibilidad material de proyectar los detalles de la construcción, estos y los referentes a la ornamentación y colorido correrán a cargo de la persona encargada de su ejecución, y que, en mi opinión debe ser artista de reputación para poder ultimarlo con feliz éxito para el día prefijado en el itinerario oficial. El costo aproximado de este trabajo lo aprecio en 4.150 pts., o sea, en 1.540 pts. la armazón; 2.210 pts. el hierro y pinturas; y las 400 pts. para los accesorios, colocación y desarme». AHMC, Fiestas, caja 968. 


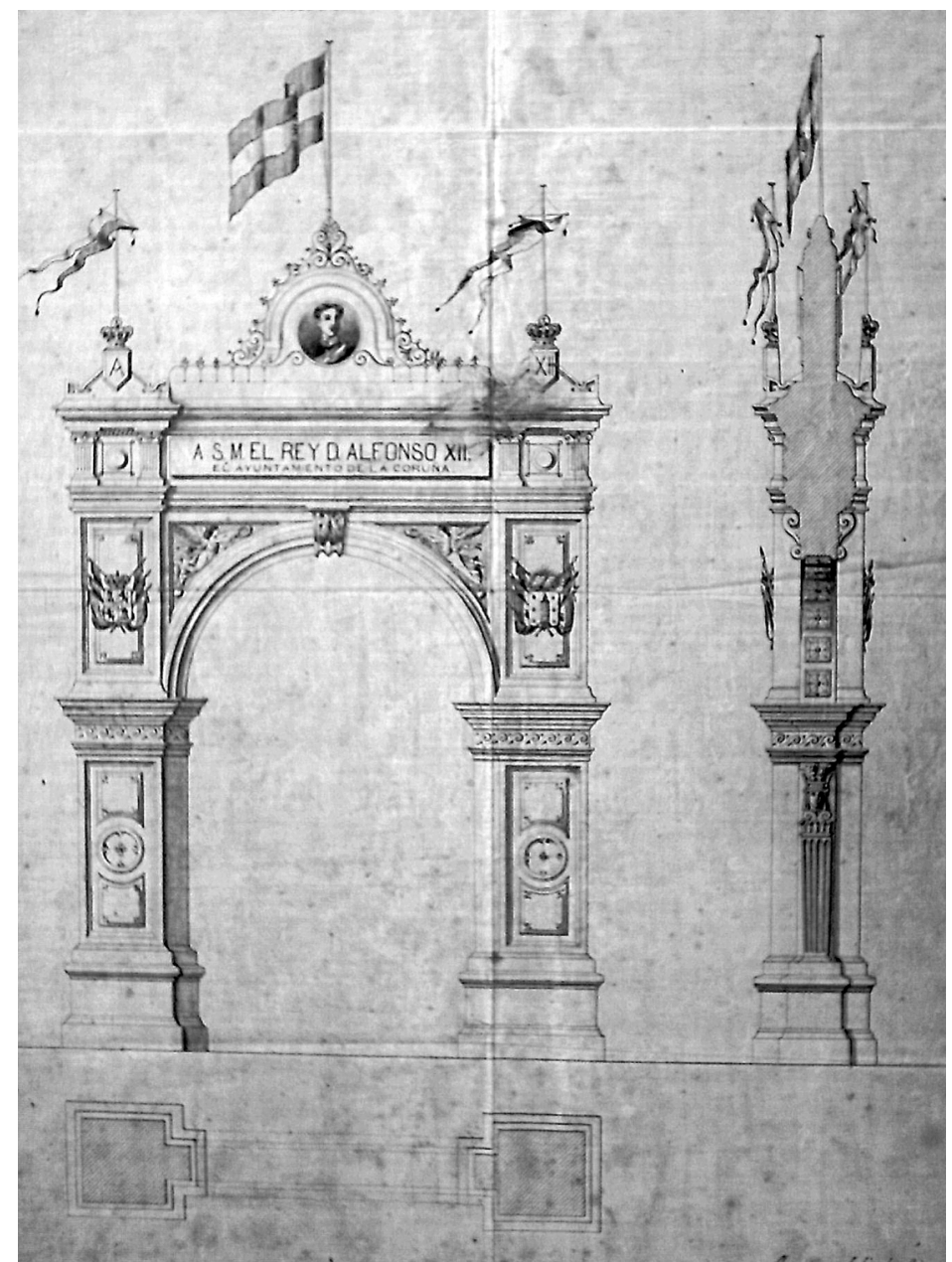

Fig. 4. Arco de triunfo para Alfonso XII en A Coruña, 1877. AHMC, Fiestas, caja 968, planero.

acometimientos de la general de la calle serían como mínimo dos, de hierro o plomo, que se colocarían por el interior, y que las llaves de paso deberían ser de latón.

La cuarta es posiblemente la más interesante, ya que indica cómo debe construirse un arco efímero reutilizable: «se construirá de piezas de armar y desarmar, para poder usarlo a voluntad" y los bastidores, cornisas y accesorios se sujetarán con clavijas, pasadores y tornillos, señalando con números o letras la unión de unos y otros. 
Las dos últimas condiciones $-5 .{ }^{a}$ y $6 .{ }^{a}$ - hacen referencia a los costes y pagos, indicando que los jornales, materiales y gas que se consuman en la construcción y colocación del arco, así como la iluminación del mismo en los días que esté aquí el monarca, y el desarme y traslado de todos los componentes hasta el almacén del ayuntamiento -incluidos los aparatos de gas, llaves de paso y tuberías-correrán a cargo del contratista. Se indica también que todas las piezas son propiedad del ayuntamiento y que el pago de la obra se realizará en dos plazos iguales, «el primero el día 28 del corriente (...) una vez colocado en el sitio designado y completamente terminado hasta en sus menores accesorios, y el segundo al deperitarse (sic) todas las partes del armazón, bastidores, escudos, coronas, banderas, remates, tuberías de gas, llaves, engranes, araña, candelabros, boquillas, bombas y demás accesorios en los almacenes del Excmo. Ayuntamiento».

Al final fueron el maestro ebanista Joaquín de la Torre y el afamado pintor Leon Bianchi y Alejandri ${ }^{17}$ quienes construyen el referido arco triunfal siguiendo las condiciones anteriormente indicadas, por la cantidad de 4.000 Ptas. ${ }^{18}$.

Como se puede observar en la imagen, es un arco de dos fachadas y un sólo vano, de $7 \mathrm{~m}$ de ancho por $10^{\prime} 5 \mathrm{~m}$ de alto aproximadamente, que destaca por la multiplicidad de elementos decorativos como molduras, volutas, relieves, torres de Hércules, coronas, escudos, banderas, destacando en el centro la imagen del monarca a modo de frontón, situada sobre la cartela conmemorativa.

Por el coste y laboriosidad del arco, por la importancia dada al almacenaje de las partes del mismo y por los documentos hallados de años posteriores se deduce que posiblemente el Ayuntamiento decidiese amortizar el gasto y reutilizarlo, emplazándolo igualmente en el paseo de Méndez Núñez durante las fiestas de M. ${ }^{a}$ Pita los años siguientes, pues de la cuenta de gastos de 1878 se desprende: «satisfecho (...) al director de la fábrica de gas por el alumbrado del arco de triunfo según cuenta y recibo n. ${ }^{\circ} 19,47,50$ Ptas. (...) Ídem a don Joaquín de la Torre por recomponer y armar el arco de triunfo en dicho paseo según cuenta y recibo $n .{ }^{\circ}$ 22, 875 ptas. ${ }^{19}$. También se indica en 1879 que «durante las fiestas lucirá a la entrada del paseo de Méndez Núñez un suntuoso arco de triunfo erigido por el Excelentísimo Ayuntamiento. Dicho arco estará adornado con vistosos grupos de banderas nacionales y gallardetes, iluminándose por la noche con profusión de lu-

${ }^{17}$ El taller Bianchi ya aparece en las cuentas de gastos del Ayuntamiento y del Círculo de Artesanos de 1868-1885 por trabajos diversos: ornatos de Carnaval, venida de Amadeo de Saboya, catafalco para la reina María de las Mercedes, decoraciones para el funeral de Alfonso XII, etc. AHMC, Fiestas, cajas 967, 968 y 971; ACAC, Libros de actas (1870-1871), 31/8/72 y ESTRADA CATOYRA, F., Contribución a la historia de la Reunión Recreativa e Instructiva de Artesanos, La Coruña, Reunión Recreativa e Instructiva de Artesanos, 1986, pág. 138.

${ }^{18}$ AHMC, Fiestas, caja 968.

19 Ibídem. 
cería de gas» por lo que se paga «a don Joaquín de la Torre por armar y desarmar el arco de triunfo según relación n. ${ }^{\circ} 16,625$ Ptas. ${ }^{20}$.

Cuatro años más tarde, el 13 agosto 1881 «amaneció la capital de Galicia vestida de gala. Arcos de triunfo a los cuales se les estaba dando la última mano, colgaduras en los balcones, alborozo en los semblantes, preparativos para las iluminaciones magníficas e incomparables, el puerto ofreciendo, en tierra como en el mar, el más bello golpe de vista que concebirse pueda» ${ }^{21}$.

El motivo no era otro que la tercera visita de Alfonso XII, al que se homenajeó mediante tres arcos de triunfo promovidos por otras tantas entidades locales. El del Ayuntamiento y el Ejército eran de estilo clásico y poco innovadores - similares a los ya vistos-, pero el de la Diputación era de estilo mudéjar, el primero y único que se levantó en esta ciudad, aunque en el resto de España y desde el reinado de su madre Isabel II, fue uno de los estilos preferidos para la realización de elementos decorativos y arquitecturas efímeras, hasta el punto de ser el estilo que representaba a España en las Exposiciones Universales de finales del siglo XIX, por recordar a la mezquita de Córdoba y a la Alhambra de Granada, monumentos muy valorados en el exterior durante esa época.

Cuando en 1881 los reyes desembarcaron fueron conducidos a una marque$\operatorname{sina}^{22}$ (fig. 5 (9)) —también efímera y mudéjar-y más tarde, a través de las calles principales, a la actual zona del teatro Rosalía, donde la Diputación Provincial había erigido «un esbelto arco triunfal (fig. 5 (8)) de purísimo estilo mudéjar, de grandes proporciones, que representaba la entrada de una ciudad árabe, flanqueada por dos torrecillas coronadas por cúpulas, en cuya cima flotaba el pabellón nacional. Dicho arco ha sido ideado por el arquitecto Faustino Domínguez, co-

\footnotetext{
${ }^{20}$ AHMC, Fiestas, caja 969.

21 lbídem.
}

22 En el malecón se había dispuesto un hermoso «pabellón ochavado de estilo mudéjar, o sea, de arquitectura arábigo española, salvo algún anacronismo e incorrección, que no deslucían el efecto del conjunto, haciendo aparecer la marquesina como un camarín morisco robado a la Alhambra de Granada. Rasgábanlo dos puertas y seis ajimeces, con grandes cortinajes. La bandera española flotaba en lo más alto del pabellón de que tratamos, y en los cuatro ángulos campeaban los escudos de las provincias de Galicia, con sus correspondientes pendoncillos asimismo de los colores regionales. Del techo pendía una linda araña para gas; una sillería de damasco carmesí, compuesta de divanes y sillones, amueblada la marquesina, y, por último, el piso estaba convenientemente alfombrado. Pedestales con bustos de personajes y con jarrones de flores formaban calle a entrambos lados, rematando con dos altos mástiles encintados de rojo y amarillo, donde dejaban al aire sus pliegues otras tantas grandes banderas españolas. Una amplia escalinata, terminada en una meseta flotante, también de buenas proporciones, forrado todo ello de hule fuerte imitando mosaico, servía de embarcadero real (...). Desde la marquesina hasta los Cantones, en toda la extensión de la ancha avenida frente a Santa Catalina, mástiles venecianos, exornados con blasones y banderolas, coronados por gallardetes, unidos por guirnaldas de faroles de colores, alzábanse teniendo a la derecha el paseo y a la izquierda, los jardines de Méndez Núñez». Ibídem. 
Arcos de triunfo efímeros erigidos en la ciudad de A Coruña para los monarcas...

rriendo la construcción y el decorado a cargo del pintor adornista Sr. Rodríguez, quien por falta de tiempo indudablemente no pudo dar a su obra todo el bulto a la par que enriquecerla con los detalles todos propios del estilo — pródigo en minucioso ornato- que el completo del pensamiento requería» ${ }^{23}$.

Como se observa en la imagen, es un arco de un sólo vano - con forma de arco polilobulado de herradura peraltado, posiblemente enmarcado en un alfiz-, limitado por dos torres de planta poligonal que semejan minaretes. El cuerpo central del arco es la parte más decorada, destacando la zona superior por los arquillos en forma de herradura, almenas y otros elementos decorativos que el dibujo no permite precisar, aunque se supone que serían de tipo epigráfico.

El arco triunfal que promovió el Ayuntamiento (fig. 5 (6)) constaba de dos fachadas y un vano, era de estilo dórico, muy sencillo y sobrio, por lo que sus elementos decorativos se limitaban a la cartela de bienvenida y a las típicas banderas, coronas y escudos, tal y como vimos en los ejemplos precedentes. Otros detalles nos los ofrece el cronista: «Era el arco triunfal erigido por el Excmo. Ayuntamiento, arco de correcto orden dórico y de esbeltas proporciones arquitectónicas, dispuesto para ser iluminado por gas con bombas de cristal y engalanado con escudos, coronas, una dedicatoria del Municipio a SS. MM., y banderas entrelazadas de España y Austria, amén del pabellón nacional que ondeaba, repetido, sobre el frontón del arco". En la cuenta de gastos del Ayuntamiento se indica que se emplearon tejidos de damasco, lana y percalina de colores — principalmente encarnadospara banderolas y que "se pagó a Manuel Rodríguez por restaurar y colocar un arco de triunfo en el puente del desembarcadero y por pintar los mástiles colocados a lo largo de todo el malecón, 1051 pts.»24, lo que sugiere —corroborado por su parecido físico- que este arco era posiblemente el que ya se había utilizado en la visita que el mismo monarca había realizado en 1877-, como sucediera con el que se recibió a su madre Isabel II en 1858 pues sirviera previamente para recibir en 1852 a los duques de Montpensier, tíos de Alfonso XII.

El arco promovido por el Ejército (fig. 5 (7)) estaba situado en la plaza del palacio de Capitanía y era mucho más elaborado. Lo más destacable es que tenía tres vanos y en consecuencia, es el único ejemplo de esta tipología del que hay constancia en la ciudad de A Coruña. Aunque en el dibujo no se aprecia claramente, parece que era de orden dórico, tenía 4 fachadas y numerosos relieves y detalles decorativos, tal y como se desprende de la descripción realizada por el cronista: "otro arco de triunfo -imitación de la Puerta de Alcalá de Madrid- dedicado por la guarnición a SS. MM. constaba de un arco central y otros dos me-

\footnotetext{
${ }^{23}$ Ibídem.

24 Ibídem.
} 


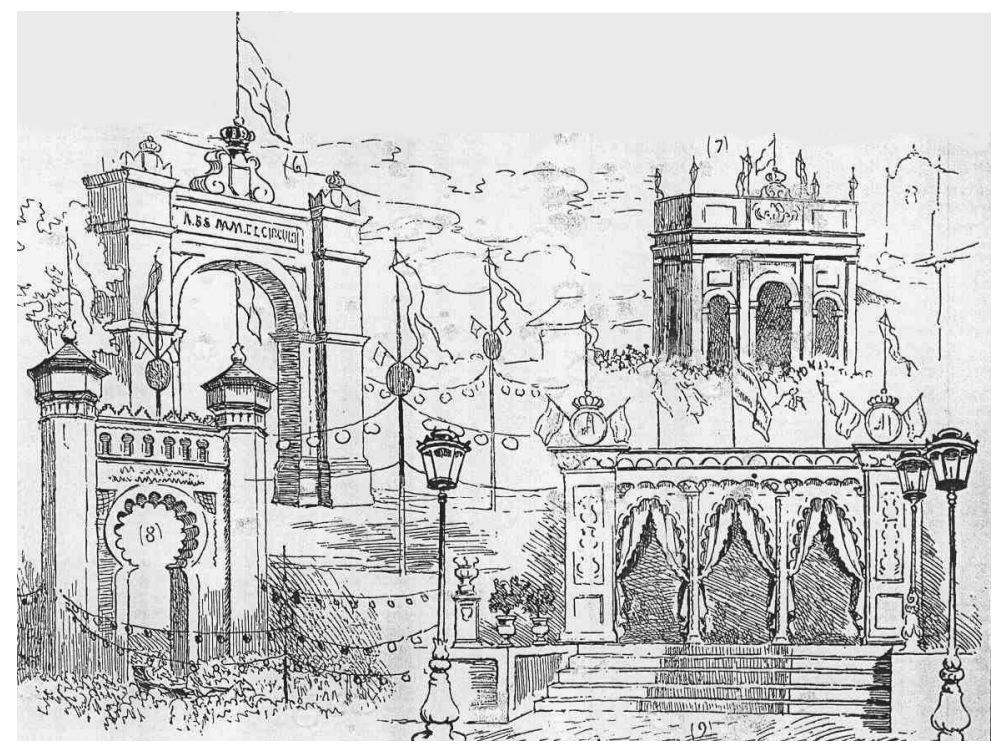

Fig. 5. Arcos de triunfo para Alfonso XII en A Coruña, 1881. Revista La llustración gallega y asturiana, $n .^{\circ}$ 25, 8/9/1881, pág. 295.

nores, laterales, coronado el todo por un gran ático, que en la parte frontera al palacio ostentaba un frontispicio, cuyo triángulo recortábase graciosamente sobre el conjunto. La bandera española, amén de pendoncillos sobre escudos en que estaban pintadas las cruces de las cuatro Órdenes militares: Santiago, Calatrava, Montesa y Alcántara, rojas y de diversas formas las tres primeras y de verde la última, daban sus pliegues al viento ${ }^{25}$.

Este viaje fue histórico para la ciudad coruñesa, pero especialmente desde el punto de vista artístico dado que fue el único acontecimiento que generó arquitecturas efímeras de estilo mudéjar y arcos de triunfo de tres vanos en la ciudad herculina.

1883 es recordado por los coruñeses porque vino Alfonso XII pero sobre todo porque se inauguró el tan ansiado y solicitado ferrocarril —iniciado en 1858 con Isabel II-que después de tantos retrasos en las obras iba a unir finalmente las provincias gallegas con el resto de la península y acercarlas así al progreso ${ }^{26}$. En

25 Ibídem.

${ }^{26}$ En el programa de fiestas oficial puede leerse: «después de largos años de dolorosa espera, durante los cuales otras comarcas de la Nación, no más merecedoras, pero sí mucho más afortunadas que la nuestra, se han visto cruzadas de caminos de hierro, La Coruña, y con ella Galicia entera, contemplan convertido en realidad el tan anhelado ideal de sus hermosas aspiraciones. El ferrocarril que con la 
Arcos de triunfo efímeros erigidos en la ciudad de A Coruña para los monarcas...

consecuencia los festejos se hicieron, no sólo para agasajar al monarca, sino para festejar un hecho histórico, y lo que es más importante, para promocionar la ciudad ante los numerosos reporteros acreditados que vinieron de otras provincias y países.

En el programa de las fiestas puede leerse: «la carrera se hallará engalanada con mástiles venecianos, trofeos, banderas nacionales, colgaduras, arcos de triunfo y caprichosas arcadas, ostentando la calle de Riego de Agua una magnífica decoración en forma de túnel, costeada por los vecinos de dicha espaciosa vía, y espléndidamente iluminada con profusión de bien combinados faroles de colores» 27 .

Se conoce la existencia de al menos dos arcos de triunfo levantados para este evento, el promovido por el Ayuntamiento y aquel propuesto por la Diputación. Se desconoce la forma de ambos, pero se supone que serían los que se habían utilizado en las visitas anteriores del monarca porque en los documentos consultados se emplean términos como armar o recomponer, y porque la creación de un arco de triunfo en esta época costaría alrededor de 5.000 pts., mientras que en la cuenta de gastos del Ayuntamiento se indica que el coste apenas supera las 1000 pts. y que corresponde al ensamblaje de los diferentes elementos, no a la invención de un nuevo arco: «satisfecho a José Lodeiro ${ }^{28}$ por recomponer y pintar el arco que se colocó en la calle Real, según cuenta y recibo n. ${ }^{\circ} 94-1.325$ pts. ${ }^{29}$.

Otro documento en el que se hace referencia a un arco de triunfo es la carta enviada el 6 de agosto por el arquitecto provincial —Faustino Domínguez- para solicitar al alcalde «permiso para levantar dos pequeños tramos de embaldosado en la calle Real, para armar el arco de triunfo que la Excma. Diputación levanta con motivo de la venida a esta capital de S. M. el Rey (q. D. g.) »30. El alcalde respondió de manera afirmativa a condición de volver a dejar dicho empedrado en el mismo estado en que se encontraba.

corte nos une, enlazando a la muy leal ciudad de Hércules con toda la Península y con Europa toda, ha dado paso ya al primer tren directo, y desde el día $1 .^{\circ}$ de septiembre daráselo diaria y regularmente a los que nos han de traer la perfección agrícola, el desarrollo fabril y comercial, el florecimiento artístico y literario, a la par del de las ciencias, los progresos o todos, en una palabra, haciendo entrar a esta gran región tan digna de próspera suerte por sus virtudes domésticas y cívicas, en el concierto de los pueblos más cultos del mundo civilizado. La primera población gallega, La Coruña, capital de las cuatro provincias hermanas, no podía, no, permanecer indiferente a este fausto suceso, que grabado debe ser con letras de oro en los anales de la historia patria». VV. AA., Grandes fiestas que el Excmo. Ayuntamiento y ciudad de La Coruña realizarán para solemnizar el fausto acontecimiento de la inauguración del ferrocarril en $1 .^{\circ}$ de septiembre de 1883. A Coruña, Tipografía Galaica, 1883, pág. 3.

27 Ídem, págs. 7-8 y periódico LVG, A Coruña, 1/8/1883.

28 José Lodeiro realizó varios trabajos como pintor para el Ayuntamiento y debió ser un artista de renombre en su tiempo pues se han encontrado varios documentos relacionados con su persona. AHMC, Teatro Rosalía de Castro, caja 3; AHMC, Jardines, caja 611; AHMC, Fiestas, caja 1044.

${ }^{29}$ AHMC, Fiestas, caja 970.

30 lbídem. 


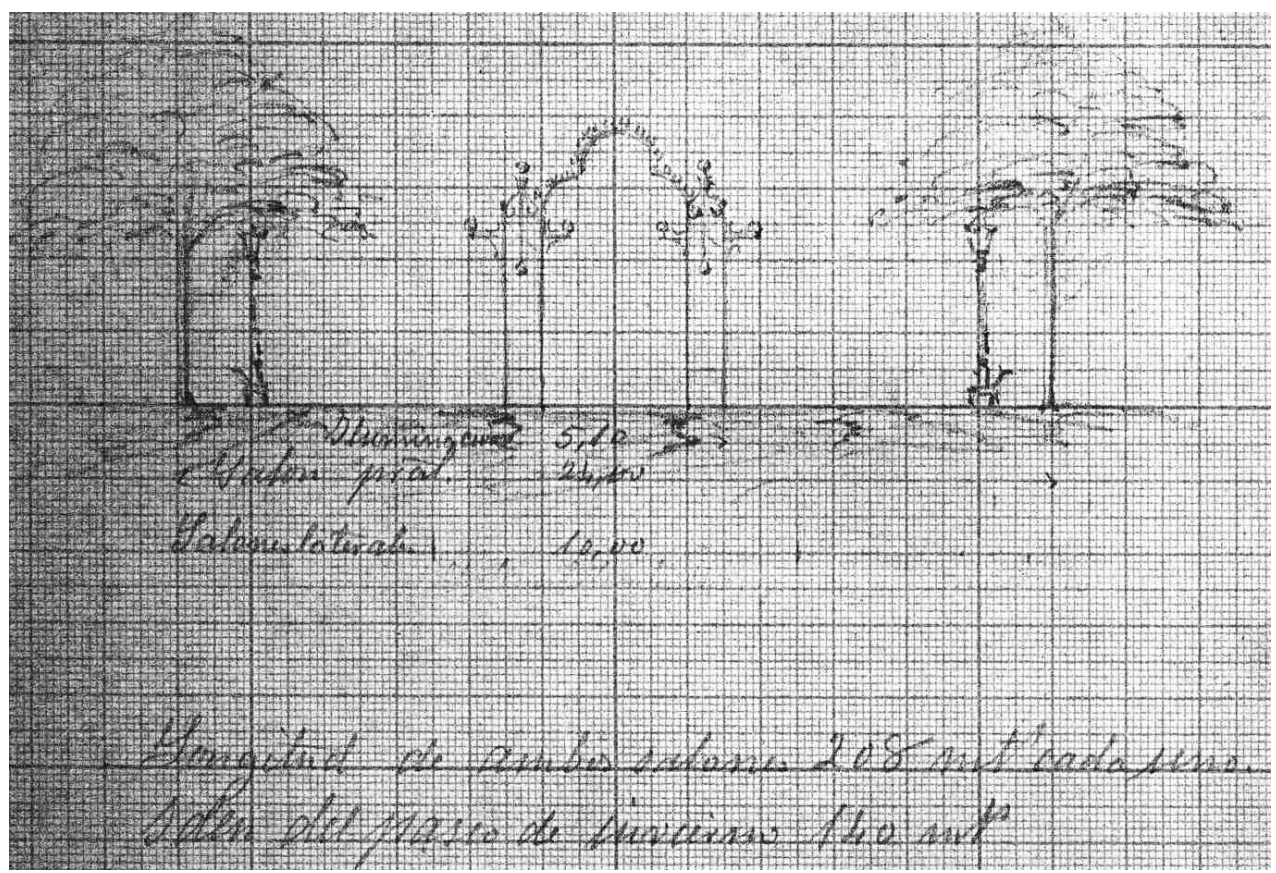

Fig. 6. Arco lumínico para Alfonso XII en A Coruña, 1883. AHMC, Fiestas, caja 970.

También se proyectó un volcán artificial ${ }^{31}$, se quemaron dos estructuras de fuegos de artificio diseñados con gran inventiva y exquisitez por la empresa "Alonso e Hijos", siendo la estructura de uno de ellos de estilo chinesco "adornada con un sinnúmero de luces con varias mutaciones de colores, guirnaldas de sorpresas, girasoles, obeliscos y otros accesorios, ocupando una extensión de $16 \mathrm{~m}$. por $10 \mathrm{~m}$. de elevación y en la que aparecería un gran transparente", y la estructura del otro de estilo gótico y «adornada con un sinnúmero de luces de colores, guirnaldas, girasoles y otros accesorios, ocupando una extensión de $20 \mathrm{~m}$. por $15 \mathrm{~m}$. de eleva-

${ }^{31}$ El Sr. Mesa, Marchesi y Martínez, de la refinería de petróleo de A Coruña, envió una carta el 25 de agosto al alcalde, en la que decía: «Deseando asociarnos de algún modo a las públicas manifestaciones de regocijo con que La Coruña se dispone a celebrar la inauguración del ferrocarril, hemos concebido el proyecto de establecer, en una de las noches de festejos, un volcán artificial en la isla llamada de los Judíos, inmediata a nuestra fábrica de refinación de petróleo. Al tener el honor de participarlo a V. S., le rogamos se sirva a su vez ponerlo en conocimiento del Sr. Comandante de Marina de esta provincia, solicitándole la competente autorización». Éste respondió que no encontraba reparo ni pondría obstáculo alguno al simulacro de volcán, añadiendo que era su deber «advertir que si las condiciones del viento reinante no son completamente apacibles, o se esparciese petróleo en la bahía, correrían riesgo los buques surtos en ella, exponiendo el puerto a una conflagración; así pues, es muy importante que las personas que dirijan esta operación sean cautas e inteligentes». Ibídem. 
ción, y en la que aparecería una inscripción alegórica» ${ }^{32}$, y se diseñó además un alumbrado en el paseo de Méndez Núñez del que se conserva un boceto (fig. 6) y las bases de construcción ${ }^{33}$ ya que la luz a finales del siglo XIX $-\mathrm{y}$ en consecuencia los arcos voltaicos o lumínicos - era un gran recurso ornamental por su innovación. De hecho, el Círculo de Artesanos «además de tener engalanada la moderna y espaciosa calle de Juana de Vega durante los días de los festejos, ostentará en toda ella una iluminación a la veneciana por medio de caprichosos arcos que ofrecerá un aspecto deslumbrante y será amenizada por las diferentes bandas militares y multitud de globos y voladores y fuegos de diversa lucería»34.

Poco más se ha encontrado. Los reyes permanecieron sólo dos días en la ciudad, pero todo ello originó unos gastos de casi 40.000 pts., que no se especificarán porque los trabajos, materiales y artistas son básicamente los mismos, sin embargo, se debe resaltar que en pintura, tejidos y adornos se gastaron casi 3.500 ptas. ${ }^{35}$, lo que permite imaginar la magnitud del evento, contrario a lo que sucedió en Lugo $^{36}$.

32 lbídem.

33 «1. ${ }^{a}$ El Director de la fábrica de gas se compromete a traer del extranjero y colocar con dos días de anticipación al primero de septiembre próximo la correspondiente tubería y candelabros que se consideren necesarios para lucir en el salón del paseo de Méndez Núñez una iluminación de gas fluido en la forma representada precisamente por el diseño aceptado por esta comisión y exhibido a ella por dicho Director, en la cantidad máxima de 18.000 pts. (...) Las 22 farolas actuales se sustituirán por grupos o ramilletes de 10 luces intercalándose otras 20 columnas de madera imitando a las actuales con iguales grupos. De columna a columna se pondrá un cordón a rampa de caño de hierro batido con largo de 9'95 m., conteniendo 4 luces con bombilla por metro. Los fondos del mencionado salón se adornarán en esta forma: El de la parte Sur con una arcada compuesta de un arco central y dos laterales, terminados por un trofeo de banderas y estrellas el primero y de estas últimas tan sólo los otros dos. El de la parte Norte o punto opuesto con un tipo de trofeo alegórico formado por la torre de Hércules, palmas, etc., con bombillas y cintas de gas. Las luces que constituyen estos dos fondos serán de color. Las 420 luces de las 42 columnas y 3.600 de las 40 rampas serán colocadas en bombillas de $15 \mathrm{~cm}$. de vidrio color opal. (...) 3. ${ }^{a}$ Todo el material que es objeto de esta iluminación se entenderá de la propiedad del Excmo. Ayuntamiento. 4. ${ }^{a}$ Dicho alumbrado lucirá en las dos noches que quedan indicadas desde las siete hasta las doce de cada una de ellas». Ibídem.

${ }^{34}$ Periódico LVG, A Coruña, 1/8/1883.

35 «Satisfecho a José Lodeiro por material y jornales empleados en la pintura de mástiles, según cuenta y recibo n. ${ }^{\circ} 92$ - 175 pts. Id. a D. José Martínez de los Céspedes por 300 escudos de cartón pintados al óleo, según cuenta y recibo n. ${ }^{\circ} 93$ - 300 pts. (...) Id. a Agapito García por adornar la fuente del jardín de Méndez Núñez, según cuenta y recibo n. ${ }^{\circ} 95$ - 17’5 pts. Id. a Nicasio Fernández por mirto y follaje, según cuenta y recibo n. ${ }^{\circ}$ 96. Id. a Francisco Bello, por pintar los aparatos para iluminación del paseo de Méndez Núñez, según cuenta y recibo n. ${ }^{\circ} 97$ - 124’5 pts. (...) Id. a D. Nicolás Boado por componer y pintar tres caretones de los enanos, según cuenta y recibo n. 109 - 30 pts.». AHMC, Fiestas, caja 970 .

${ }^{36}$ Allí no se celebraron grandes festejos porque además de preferir destinar el dinero a la feria y fiesta de San Froilán, eran conscientes de que «breves instantes permanecerá en la estación de Lugo la regia comitiva, siendo La Coruña el punto de detención, donde pueden y deben hacerse grandes fiestas; porque allí acudirá inmenso gentío». ABEL VILELA, A., Personajes reales en Lugo, A Coruña, Ediciós do Castro, 1983, pág. 201. 
Mientras que Alfonso XII fue el monarca que más nos visitó —pues vino en $1858,1877,1881,1883$ y 1884 - su hijo Alfonso XIII nos visitó -ya en el siglo $\mathrm{xx}$ - en tres ocasiones, erigiéndole dos arcos de triunfo en la visita de 1909. A partir de entonces y debido a la coyuntura política española, no se levantarán más arcos de triunfo para monarcas, sino para el nuevo Jefe del Estado Francisco Fran$\mathrm{co}$, quien copió los modelos del nazismo y fascismo en los actos propagandísticos, ceremoniosos y grandilocuentes realizados al aire libre, que tenían como fin conseguir la adhesión civil y aumentar el fervor popular.

En resumen, los diferentes monarcas españoles que vinieron a tierras coruñesas durante la 2. ${ }^{a}$ mitad del siglo XIX lo hicieron por motivos variados -reconocer el territorio, veneras al apóstol, inaugurar línea de ferrocarril, etc.- y para agasajarles, las diferentes entidades locales — principalmente el Ayuntamiento (5), la Diputación (2), el Círculo de Artesanos (1) y el Ejército (1) - fueron los promotores de los nueve arcos de triunfo que se levantaron y que se situaron en la calle Real o en el paseo de Méndez Núñez.

Así, para Isabel II se erigieron tres arcos de triunfo en 1858, dos convencionales — uno reutilizado y otro de estilo clásico-y otro vegetal-; y para Alfonso XII se construyó uno clásico en 1877, tres en 1881 —dos de estilo clásico (uno reutilizado) y uno islámico-y dos en 1883 , ambos reutilizados.

Es decir, se crearon 4 arcos de triunfo nuevos y se reutilizaron otros tantos -algunos, como el de 1877, hasta en dos ocasiones más-, posiblemente porque se encontraban en buenas condiciones dado que se emplearon en un reducido intervalo temporal y porque las entidades carecían de recursos económicos, deduciéndose que la arquitectura efímera coruñesa, principalmente aquella de carácter conmemorativo, no sólo es fruto de la coyuntura histórica y política o del estilo artístico imperante en ese momento, sino y sobre todo, de la situación económica de la ciudad.

De los arcos de triunfo levantados en la segunda mitad del siglo XIX en la ciudad de A Coruña, en un tiempo y espacio afín la monarquía, se puede concluir que su cantidad fue estimable, pero no tanto su innovación - sobre todo desde el punto de vista tipológico y decorativo-, dado que ésta fue muy limitada, y es que los materiales - generalmente madera, textil y cartón-y los ornatos - generalmente coronas, escudos y banderas- eran similares a los que se veían en otras ciudades, y los artistas participantes - escenógrafos, pintores, decoradores, carpinteros, además del arquitecto municipal- pertenecían a un sector muy endogámico que participaban principalmente en los eventos locales y tenían poca relación con el exterior. 